\section{gestão tecnológica}

\section{Introduçāo; \\ 2. Tecnologia e estrutura organizacional; 3. Organizaçāo e rentabilidade; 4. Algumas palavras sobre a tecnologia; 5. A dimensäo organizaçäo; 6. A dimensäo tecnologia; 7. A dimensāo rentabilidade; 8. Definiçäo das variáveis; 9. $O$ modelo relacional.}

\section{Tecnologia, organizaçãoe rentabilidade: um modelo para investigação empirica}

\author{
Indiana Pinheiro da Fonseca Rodrigues \\ Do CMA/DCA/UFMG.
}

Uma revisðo bibliográfica da teoria administrativa permitiu-nos construir um paradigma para conceituação das três dimensóes do modelo. Partindo das dimensóes conceituadas, definimos as unidades de análise. Dentro de cada unidade de análise foram definidas as categorias e as variáveis representativas para o estudo.

A proposta de investigar as relaçбes entre tecnologia, organizaç̧o e rentabilidade resulta de algumas indagaçóes, para as quais buscamos resposta. A ampla literatura existente sobre $O$ assunto, evidentemente, não o esgota, mas antes faz emergir novas hipóteses, em particular quanto à natureza e extensráo dessas relaçoes.

O modelo que sugerimos propóe analisar as relaçoes entre variáveis da tecnologia, da estrutura e dinâmica organizacional e da rentabilidade das empresas, no sentido de esclarecer:

a) quanto da estrutura organizacional é explicado pela tecnologia e quanto $\epsilon$ explicado por variáveis políticas; b) que variáveis da tecnologia, da estrutura e da política organizacional estáo relacionadas com a rentabilidade $e$ qual a natureza dessas relaçoes; c) qual o comportamento dessas variáveis em diferentes tipos de empresas.

\section{TECNOLOGIA E ESTRUTURA ORGANIZACIONAL}

Estudos da organizaçáo têm evidenciado a existência de correlaçáo entre a estrutura organizacional e a tecnologia em diferentes organizaçoes. Um dos trabalhos mais relevantes neste campo, e que tem, inclusive, orientado muitas pesquisas posteriores, é o de Woodward (1977).

Levando a cabo exaustiva pesquisa em cem empresas na região de South Essex, no período de 1953 a 1963, Woodward empreendeu uma análise do comportamento administrativo dessas empresas, com suporte nos conceitos e ideais da teoria clássica da administraçáo. Os resultados dessa pesquisa mostraram nao somente que a tecnologia é uma variável determinante da estrutura da organizaçáo, mas tarnbém que as empresas bem-sucedidas comercialmente, dentro de cada sistema de produção específico, tinham caracteristicas comuns em suas formas de organizaçao. Nas palavras da pesquisadora, "o fato de as características organizacionais, a tecnologia e o sucesso estarem ligados desta maneira sugere ño apenas que o sistema de produçáo era uma variável importante na determinaçáo da estrutura organizacional, mas também que uma forma particular de organizaçáo era mais apropriada para cada sistema de produça" (Woodward, 1977, p.77).

No campo de trabalhos empíricos no Brasil, a pesquisa de Coelho (1978), realizada em 69 empresas do estado da Guanabara, constatou considerável efeito da variável tecnológica (definida pela razáo capital/trabalho) sobre variáveis da estrutura organizacional.

Neste estudo, argumentamos que, a nivel operacional, a tecnologia é forte determinante da estrutura organizacional, mas que, a nível administrativo, a forma organizativa parece ser determinada por outras variáveis que não a tecnologia. A definição destes.dois níveis pode ser feita seccionando-se a estrutura da organizaçáso através do estabelecimento de uma fronteira que separe o campo operacional e o campo administrativo. 0 campo operacional fica definido como a seçato da estrutura que agrega o complexo dos departamentos de produça e serviço, configurando todas as demais unidades organizacionais o campo administrativo (esta divisáo será pormenorizada mais adiante).

Para Perrow (1972), o desenvolvimento de organizaços burocráticas é decorrente da necessidade de especializaçăo, de controlar influências de fatores externos e de lidar com um ambiente mutável e instável. Segundo ele, "para fazer frente aos problemas criados pelo contexto ambiental dos seus membros, as organizaços desenvolveram dois métodos, que nada tém a ver, diretamente, com o processo produtivo em si, isto é, nada têm com o trabalho do operário, no que se refere da matéria-prima, recebida por ele". 1 . Outros estudos tém mostrado que parte da estrutura organizacional é explicada por outras variáveis do ambiente, além da tecnologia, influência que se dá através do processo de interaçăo da organizaçăo com o ambiente (Lawrence \& Lorsch, 1973; Thompson, 1967; Hall, 1972). Tambem a pesquisa de Woodward 
(1977) levantou uma série de razoes não-tecnológicas, identificadas como propulsoras da criaçáo de departamentos especializados na indústria de South Essex.

A comprovaçáo dessas relaçбes parece já bastante cristalizada na teoria organizacional, por isso sentimonos desejosos de dirigir parte de nossas investigaçбes para o campo da dinâmica intra-organizacional. Para tanto, encampamos 0 argumento de Bacharach \& Lawler $(1980, p .1)$ de que as "organizaçóes náo săo as entidades racionais e harmoniosas, como pretende a teoria administrativa, nem a arena apocaliptica de luta de classes, como preconizam os marxistas". Segundo estes autores, uma visão mais realista requer uma teoria política capaz de propiciar um modelo de análise das relaçoes entre as personagens e os grupos dentro da organizaçáo. Neste sentido, tentamos estudar os processos organizacionais como atos políticos capazes de explicar alguns formatos estruturais.

$\mathrm{Na}$ realidade, a observação de relaçós informais nas organizaçóes não é nenhuma novidade. Desde os estudos de Elton Mayo, elas foram identificadas e têm sido amplamente tratadas na literatura. Contudo, a psicologia industrial e organizacional, concentrada, por exemplo, nas teorias de liderança, motivação e satisfação, assume que o comportamento é motivado e controlado pela necessidade de aprovaçá e recompensa normativas. Por outro lado, como atestam Bacharach \& Lawler $(1980$, p.2), "estudos sociológicos comparativos da organização, nos últimos 15 anos, têm quase sempre adotado uma visáo apolítica das organizaçớes", criando uma tradição de estudo de estrutura estática. Ainda assim, dentro desta tradiçáo, a pesquisa de Rodrigues. \& Sá (1982) em 24 organizaçбes brasileiras, no estado de Minas Gerais, constatou que as estruturas das organizaçóes apresentavam alguns aspectos contraditórios, que pareciam refletir a influência de velhos padrótes de comportamento já cristalizados, infiltrados na estrutura racional.

Com base nestes argumentos, estamos propondo investigar o quanto da estrutura é explicado pela tecnologia e o quanto é explicado pela dinâmica intra-organizacional, havendo ainda, certamente, resíduos que podem ser explicados por outros fatores, ou náo têm explicação identificável.

\section{ORGANIZAÇÃO E RENTABILIDADE}

O uso da rentabilidade, como uma dimensáo deste estudo, requer, antes de tudo, uma definiçáo clara de seu siginificado. A palavra rentabilidade significa, para nós, o ganho que a empresa obtém do seu esforço produtivo, essencial para que ela possa remunerar os fatores de produção e continuar seu ciclo de operaçóes. Colocando nestes termos, podemos dizer que o sucesso ou o insuces. so da empresa está associado a sua rentabilidade.

Como ficou demonstrado na pesquisa de Woodward (1977), o sucesso das empresas, em cada sistema de produç̧o, estava associado a um formato particular de organizaçăo. Também Lawrence \& Lorsch (1973), pesquisando a indústria de materiais plásticos nos EUA constataram náo somente que variáveis do ambiente eram determinantes da diferenciaçáo na estrutura das empresas, mas que as empresas bem-sucedidas eram aquelas que satisfaziam a demanda do ambiente em alta diferenciaçáo e integraçáo.

Na teoria clássica da administraçáo, a orgarização eficiente do trabalho era um meio de alcançar a eficácia. Para Taylor (1963, p.13), "o principal objetivo da administraçăo deve ser o de assegurar o máximo de prosperitade ao patrão e, ao mesmo tempo, o máximo de prosperidade ao empregado". De acordo com os pressupostos da teoria clássica, deve haver uma correlçáo direta entre desempenho econômico e organizacional. Já. para Drucker (1979), a organizaçáo eficiente náo garante o sucesso, porém a ineficiência organizacional pode provocar a falêneia.

Na moderna teoria da administraçato, a medida de sucesso tornou-se discutível, pois muitos estudos têm sido realizados, tomando-se diferentes parâmetros para medir a eficácia das organizaçóes (Steer, 1975). Segundo Newbould \& Lufftman (1978, p.11), "da Idade Média até recentemente, o lucro era a medida do sucesso, a aqueles que formulavam a política de negócios acertada e dirigiam, portanto, uma empresa lucrativa eram homens orgulhosos de seus feitos e reconhecidos por seus pares, e outros membros da sociedade, pelo seu sucesso". Mas as coisas mudaram, o capitalismo moderno distanciase da forma pura do capitalismo e caracteriza-se por "uma economia, na qual as empresas não têm mais certeza de seus objetivos, onde há extenso envolvimento governamental e reivindicaçбes entre todos os setores da populaçáo sobre os propósitos das empresas e do crescimento ernnômico" (Newbould \& Lufftman, 1978, p.11-2). Estes autores sugeren que a medida do sucesso, no atual contexto econômico, depende das relaf̧oes que o avaliador mantém com a organizaçáo avaliada. Desde que estamos propondo um modelo para análise de empresas, optamos por eleger a rentabilidade como medida de sucesso da empresa; porém, a definição das variáveis que expressam, para nós, a rentabilidade irá caracterizar, sem dúvida, o ponto de vista do avaliador.

Sugerimos que tanto as variáveis tecnológicas quanto as variáveis de estrutura e dinâmica organizacionais devem apresentar algum grau de correlaçáo com a rentabilidade. $O$ que propomos é identificar as variáveis que apresentam correlaçáo com a rentabilidade e analisar a natureza dessas correlaçбes.

\section{ALGUMAS PALAVRAS SOBRE A TECNOLOGIA}

A tecnologia tem sido definida de diferentes maneiras por grande número de autores. De uma maneira geral, podemos identificar, pelo menos, duas correntes. Uma, que define tecnologia de forma abrangente, compreendendo todo o processo operacional, seja de produçáto ou de serviço, isto $\hat{e}$, todo modo de fazer coisas implica uma tecnologia específica (Thompson, 1967; Perrow, 1972). Outra corrente já define tecnologia de forma mais restrita, entendendo como tecnologia o processo de produgtio de bens, inerente aos equipamentos utilizados nes. ta produçto (Woodward, 1977; Coelho, 1978). Vamos adotar aqui a definiçáo de Sabato (1972), que serve a nossos propósitos: "Tecnologia é o conjunto ordenado 
de conhecimentos, empregados na produção e comercialização de bens e serviços, e que está integrada não só por conhecimentos cientificos - provenientes das ciências naturais, sociais, humanas etc. (. . .) mas igualmente por conhecimentos empiricos, que resultam de observaçóes, experiências, atitudes especificas, tradiçáo (oral ou escrita) etc." (Sabato, apud Barbosa, 1981, p. 19).

Historicamente, o progresso técnico se manifesta como a busca intensiva, pelo homem, de meios que lhe possibilitem melhorar sua condição de vida. Com isso queremos dizer que o ser humano, premido pela necessidade de autopreservaçá, procurou sempre aperfeiçoar seus instrumentos e métodos de trabalho, de modo a extrair mais produtos em menor tempo de trabalho e ganhar, com isso, mais tempo para descanso e lazer. Porém, até a Revolução Industrial, o progresso técnico ou sua difusão foram relativamente lentos. Pode-se dizer que a aceleração da inovação tecnológica, que caracteriza o que conhecemos hoje como Revoluçáo Industrial, foi certamente fundamental para a consolidação do sistema capitalista ocidental. Vale aqui a observação de que, ao mesmo tempo em que as invençóes disponiveis de produçáo e comercialização dos produtos propiciaram o surgimento do capitalismo, a ânsia de acumulação do sistema impulsionou o progresso técnico.

Por outro lado, numa visáo marxista, enquanto o trabalhador tinha a propriedade dos meios de produçắo, o progresso técnico foi naturalmente uma melhoria das condiçסes de vida de cada um e da sociedade como um todo. A separação do homem dos meios de produçăo é que dá um caráter particular à tecnologia. Benakouche (1982) define tecnologia como sendo um processo onde o resultado é a criação do valor. Apresenta-se, de um lado, como forma de dominaçá e meio de lucratividade $e$, de outro, como a base sobre a qual a invençăo assume um conteúdo concreto do progresso técnico. Não cabe, no espaço deste trabalho, discutir ou investigar os efeitos sociais do progresso técnico. Contudo, parece-nos evidente que todo aperfeiçoamento tecnológico teve como resultado o aumento da produtividade do trabalho e a melhoria de produto. Woodward (1977) sugere que as mudanças tecnológicas parecem ser decorrentes de decisão política de modificar objetivos, a fim de introduzir um sistema de produção mais avançado, ou resultado de um desenvolvimento, técnico ou administrativo, que tornasse possível alcançar o objetivo de uma maneira mais eficaz.

Diante deste quadro, podemos esperar que, em última instância, os efeitos da tecnologia devam refletir na rentabilidade da empresa. Se esta influência se dá de foṛma direta ou através do arcabouço organizacional, é o que desejamos investigar.

\section{A DIMENSÃO ORGANIZAÇÃO}

Em primeiro lugar, julgamos essencial deixar claro o significado da palavra "organizaçao" como uma dimensáo da empresa. Obviamente, o termo é muito amplo e é correntemente empregad̀o para designar a própria entidade, que aqui é a empresa. $O$ conceito de orgnizaçấo, na leitura corrente, enfatiza a associaçáo e cooperaçato de pes- soas, num complexo sistema de comunicaçoes e interaçóes, com o propósito de atingir certas finalidades (Simon, 1979; Blau \& Scott, 1977; Barnard, 1971). Tratar a organização como uma dimensão se justifica quando o que se pretende é investigar como se dá, empiricamente, a associação, cooperação, comunicaçáo e interação dos membros da organização. 0 organograma expressa a estrutura organizacional na sua forma estática. Essa estrutura é determinística, na medida em que prevê todo o sistema de interaçao entre os indivíduos. No entanto, a organizaçáo é uma entidade viva, por isso dinâmica, e a ação organizacional é a expressấo do processo dinâmico que se dá entre os individuos.

E com base nos aspectos estático e dinâmico da organização que selecionamos, para unidade de análise da dimensđo organização, a estrutura organizacional e a rede de influência política.

Desde que inúmeros trabalhos empíricos têm comprovado que a tecnologia e as incertezas do ambiente sáo determinantes da estrutura organizacional (Woodward, 1977; Lawrence \& Lorsch, 1973; Coelho, 1978; Perrow, 1972), pretendemos incluir, na análise, a rede de influência política da organização, para investigar até que ponto esta confrontaçáo de forças internas afeta seu formato estrutural. Da unidade de análise estruturai, as categorias selecionadas foram: especialização, centralização e configuração. A justificativa das categorias, e respectivas variáveis, será dada mais adiante.

0 aspecto político das organizaçoes não tem recebido muita atenção dos estudiosos da administração e organização (Pfeffer, 1981), o que, a nosso ver, deixa uma lacuna no corpo teórico, considerando que muitos fenômenos podem ser explicados, fundamentalmente, pelas relaçóes de poder e influência. Para análise da rede de influência política, as categorias selecionadas foram os grupos de interesse e coalizóes. Bacharach \& Lawler (1980) apontam, com base no trabalho de Dahrendorf (1959), os grupos de trabalho, os grupos de interesse e os grupos de coalizáo como sendo críticos para o desenvolvimento de uma análise política de organizaçós. Como os grupos de trabalho são definidos pelas atividades departamentais ou diferenças prescritas pela hierarquia organizacional (Bacharach \& Lawler, 1980), estarão circunscritos na estrutura da organização, não sendo por isso adequados para o tipo de relação que propomos investigar.

De acordo com o modelo teórico de Bacharach \& Lawler (1980), algumas características organizacionais facilitam ou dificultam a formação de coalizóes. Com base neste modelo, podemos levantar a hipótese de que "a organizaçáo pfocura controlar a ação dos grupos de interesses e/ou coalizőes, através do formato de sua estrutura". Por outro lado, sugerimos que a decisđo de escolha do formato estrutural da organização não é apenas uma ação racional, mas tem também um forte componente politico (Pfeffer, 1981). Desta forma, nossa segunda hipótese é de que "na medida em que os grupos de interesse e/ou coalizбes adquirem mais poder, eles procuram legitimar seu poder através da autoridade formal". Neste caso, dois caminhos se apresentam como mais prováveis. $\mathbf{O}$ primeiro poderia ser uma mudança de posição relativa na organizaço, ou seja, uma tomada de poder. 
Uma segunda via seria através de mudanças na estrutura organizacional, capaz de criar posiços de autoridade e alterar as relações de poder estabelecidas.

Como já argumentamos no início deste artigo, o efeito da tecnologia sobre a estrutura pode decrescer nos níveis não-operacionais, que chamamos administrativos. Este argumento sugere que, nos niveis hierárquicos mais altos, a rede de influência política é que melhor explica a estrutura organizacional. $O$ estabelecimento de uma fronteira que delimite os campos operacional e adminis. trativo será um dos resultados da investigação empírica sobre causas e efeitos de mudanças estruturais.

\section{A DIMENSÃO TECNOLOGIA}

Para definir as unidades de análise da dimensăo tecnologia, faremos primeiro uma revisáo da literatura na qual nos baseamos para esta definiçấo. 0 trabalho de Woodward (1977) atém-se à tecnologia de produção industrial. Através dos levantamentos na área industrial pesquisada, a autora identifica três processos industriais significativos, definidos pela tecnologia e associados às características estruturais das organizaçoes. Segundo os resultados desta pesquisa, a produção em unidades, ou pequenos lotes, a produção em massa, ou grandes lotes, e a produção por processamento implicam formatos organizacionais específicos.

O modelo de Thompson (1967) também sugere que a tecnologia é determinante da estrutura organizacional. Contudo, buscando explicar as organizaçoes genericamente, Thompson identifica três categorias de tecnologia, a partir da natureza do trabalho e do produto da organização. Assim, para Thompson, as indústrias enquadram-se na categoria de elos de seqüéncia, e as empresas, cujos serviços representam a intermediaçáo entre clientes ou fregueses; tais como bancos, enquadram-se na categoria mediadora. Por último, a categoria intensiva, segundo o autor, significa que várias técnicas sáo acionadas, a fim de alcançar uma mudança em algum objeto específico, e exemplifica com um hospital geral.

Para Perrow (1972), a tecnologia pode ser definida a partir da matéria-prima, isto é, do material a ser transformado por meio de técnicas. Com base nessa premissa, suas categorias de tecnologia sáo: artesanato, rotina, ausência de rotina e engenharia. Assim como Thompson (1967), também Perrow (1972) trata as organizaçбes de forma generalizada, porém seu modelo assume a diferenciação intra-organizacional.

A pesquisa de Lawrence \& Lorsch (1973) em indústrias de materiais plásticos, de recipientes e de consumo alimentar, nos EUA, concluiu que o grau de instabilidade do ambiente e da tecnologia estava associado a certas características estruturais destas organizaçoes e que implicava a diferenciação intra-organizacional. Os resultados empíricos da pesquisa destes autores mostram a diferenciaçáo como variável dependente do ambiente de tarefa $e$ da tecnologia.

Dentro deste quadro de referência (e considerando as especificidades do setor objeto do estudo), as unidades de análise definidas foram o processo de produça e o processo de serviço. Esta definição implica: a) que a natureza da tarefa define a tecnologia;

b) que departamentos que utilizam diferentes tecnologias teráo estruturas diferenciadas;

c) que o estudo de diferentes departamentos permite avaliar quanto da estrutura organizacional é explicado pela tecnologia.

As categorias do processo de produçáo relevantes no caso săo intermitente e contínuo. A opção por estas categorias se fundamenta em informaçoes sobre a evoluçáo tecnológica na indústria em geral, no sentido de passar do processo de produçáo intermitente para o processa. mento contínuo, com crescente índice de automação.

Para a unidade de análise processo de serviço, desde que a divisáo do trabalho é subordinada à natureza da tarefa (Braverman, 1977) e que esta define a tecnologia (Thompson, 1967), sugerimos que a tarefa apresenta-se como a categoria relevante.

\section{A DIMENSÃO RENTABILIDADE}

De acordo com a nossa proposiçáo de identificar quais variáveis organizacionais estáo relacionadas com a rentabilidade da empresa e a natureza dessas relaçoes, sugerimos, para unidade de análise da dimensáo rentabilidade, a performance econômica e financeira da empresa.

A definição dessas unidades de análise fundamentase nos argumentos de que:

a) a rentabilidade é um conceito operacional relacionado com a criação de riquezas (Solomon, 1969), sendo, portanto, uma medida da eficiência da empresa na alocação de recursos;

b) o "nível de lucros da empresa moderna é determinado pela necessidade de financiar um certo nível de investimento" (Wood, 1980), o que implica, para a empresa, uma performance econômica e financeira consoante com suas expectativas de expansáo.

O conceito de medida operacional sugere que a categoria relevante da performance econômica será dada pela lucratividade. Neste caso, a questáo que se coloca é de como medir a lucratividade das empresas, pois um número razoável de indicadores pode ser proposto. Sem dúvida precisamos agora definir nosso parâmetro de lucratividade, com base nos indicadores necessários para a análise proposta. $O$ fundamental, aqui, parece-nos ser selecionar variáveis que representem a eficiência operacional da empresa. Quanto à performance financeira, sugerimos a política de financiamento como a categoria relevante para a análise. A seleção da política de financiamento está fundamentada no argumento, da teoria de finanças, de que:

a) a empresa terá um custo de capital ótimo, no ponto em que ela obtiver o equilíbrio entre o uso de capital próprio e de terceiros;

b) aumentando o volume de capital de terceiros, a empresa pode aumentar sua rentabilidade, mas aumenta também seu risco. 


\section{DEFINIÇÃO DAS VARIÁVEIS}

Como já referimos, a definição das variáveis deste estudo foi feita a partir do desdobramento das dimensoes primárias, objeto da pesquisa. Na definição das categorias e das variáveis da estrutura, baseamo-nos, principalmente, nas definições de Pugh et alii (1968). Para medir a especialização, optamos por eleger o número de especializaçōes funcionais. $O$ instrumento de coleta de dados, neste caso, foi baseado na escala de 16 especializaçós funcionais de Pugh et alii (1968), porém adaptado para as categorias das empresas brasileiras. A categoria centralização refere-se ao locus de autoridade para tomar decisőes. Contudo, para nosso objetivo, é importante não apenas identificar a autoridade formal responsável pela decisão, mas também as pessoas envolvidas no processo. Os tipos de decisão selecionados foram:

a) sobre o formato estrutural da organização;

b) de investimento em equipamentos;

c) sobre a estrutura de capital.

$\mathrm{Na}$ verdade, trata-se de um grupo muito limitado de decisões, porém, por referirem-se, especialmente, ao tema central do estudo (a primeira à organização, a segunda à tecnologia e a terceira à rentabilidade), sáo por isso as variáveis significativas para nossos propósitos. Configuração é o próprio formato da estrutura organizacional. Neste caso, aiguns dados relevantes podem ser extraidos do organograma. As variáveis selecionadas para medir a configuração foram:

a) níveis hierárquicos;

b) proporção de empregados na produção em relação ao número total de empregados;

c) proporção de empregados administrativos em relação ao número total de empregados;

d) amplitude de controle das chefias.

O que estamos propondo é identificar fatores que explicam a configuração estrutural das organizaçóes. Aqui, sugerimos que as categorias centralizaçáo e especialização apresentam-se como indicadores dos atores da ação política intra-organizacional e, portanto, dos grupos de interesse e coalizőes. Não temos a pretensáo de fazer uma extensa análise política das organizaçఠes, mas tãosomente de identificar a influência destes grupos nos três tipos de decisóes selecionadas. Para analisar as relaçóes dos grupos, selecionamos, do conjunto de sete atributos da rede de influência de Bacharach \& Lawler (1980), as seguintes variáveis:

a) ligaçōes - que se refere ao grau de interação entre os diversos grupos;

b) sobreposição - que diz respeito à participaçăo de um indivíduo em mais de um grupo;

c) congruência - que examina se os grupos que participam do processo decisório correspondem às autoridades formais para aquelas decisóes;

d) dominância - que é a extenș̃o em que prevalece a influência de um determinado grupó.

$\mathrm{Na}$ definição das variáveis da dimensão tecnologia, nossa preocupaçăo básica foi selecionar medidas repre- sentativas da natureza dos processos de produçáo e de serviço.

Para a unidade de análise processo de produção, o grau de automaçáo, tanto na categoria intermitente, como na categoria contínuo, pode expressar, razoavelmente, a natureza do processo. Como dizem Newbould \& Lufftman (1978), para um observador externo não é fácil medir a automação. Estes autores assumem a mudança no volume de capital por empregado como um índice de automaçáo que, sem dúvida, para o estudo deles, é um indicador significativo. No nosso caso, sugerimos que uma medida adequada do grau dé automaçáo será um índice que relacione volume de produçáo e número de operadores, desde que aplicado a processos comparáveis.

Para a unidade de análise processo de serviço, o grau de totina das tarefas parece-nos a variável mais apropriada como indicador da natureza da tarefa. O conceito de rotina, segundo Perrow (1972), refere-se ao processo de transformaçăo, suficientemente conhecido para permitir a execução da tarefa, como resposta ao estímulo que o individuo recebe. Principalmente quando se trata de setores de serviço, o grau de rotina pode expressar a tecnologia e pode ser medido por uma escala de freqüência das tarefas executadas.

As variáveis representativas das categorias lucratividade e política de financiamento restringem-se a alguns indices extraídos dos rẹlatórios financeiros anuais das empresas. Ainda que, comumente, sejam feitas objeçбos a estes índices, especialmente porque eles sáo obtidos a partir de registros contábeis, sujeitos à rigidez dos princípios contábeis e às regras legais e tributárias, essas mesmas limitaçóes podem-se apresentar como vantagens, na medida em que homogenizam os registros e permitem ao analista externo apreender, com maior segurança, o significado de cada rubrica.

Para a categoria lucratividade, selecionamos algumas variáveis, que julgamos expressar a capacidade da empresa de gerar lucros a partir das operaçóes, e que são:

a) margem bruta - a relação lucro bruto sobre vendas líquidas, ou seja, o quanto da receita líquida a empresa tem depois de deduzido o custo dos produtos vendidos;

b) margem operacional - a relação lucro operacional sobre vendas líquidas, isto é, a percentagem da receita, após a dedução do custo dos produtos e das despesas administrativas e de vendas;

c) margem líquida - a relaçáo entre lucro operacional, mais a receita e menos a despesa financeira, e as vendas líquidas. Esta variável pode evidenciar também os resultados da política de financiamento.

Para identificar a politica de financiamento, selecionamos a variável grau de endividamento. A medida será obtida da análise da estrutura do passivo das empresas. isto é, da relação entre capital próprio e capital de terceiros.

O quadro 1 sintetiza as variáveis, categorias e unidades de análise de cada dimensão do estudo. 
QUADRO 1

\begin{tabular}{|c|c|c|c|}
\hline Dimensĩo & $\begin{array}{l}\text { Unidade de } \\
\text { ańlise }\end{array}$ & Categorias & Variáveis \\
\hline \multirow[t]{4}{*}{ Organização } & Estrutura & Especialização & $\begin{array}{l}\text { - Número de espe- } \\
\text { cializaçōes fun- } \\
\text { cionais. }\end{array}$ \\
\hline & & Centralização & $\begin{array}{l}\text { - Autoridade na } \\
\text { tomada de deci- } \\
\text { sōes: } \\
\text { - de financia- } \\
\text { mento } \\
\text { - de investimen- } \\
\text { to } \\
\text { - de formato es- } \\
\text { trutural }\end{array}$ \\
\hline & & Configuração & $\begin{array}{l}\text { - Amplitude de } \\
\text { controle. } \\
\text { - Número relativo } \\
\text { de empregados } \\
\text { administrativos. } \\
\text { - Número relativo } \\
\text { de empregados } \\
\text { na produção. } \\
\text { - Niveis hierárqui } \\
\text { cos. }\end{array}$ \\
\hline & $\begin{array}{l}\text { Rede de } \\
\text { influência } \\
\text { política }\end{array}$ & $\begin{array}{l}\text { Grupos de } \\
\text { interesses e } \\
\text { e coalizōes }\end{array}$ & $\begin{array}{l}\text { - Ligaçōes } \\
\text { - Sobreposição } \\
\text { - Congruência } \\
\text { - Dominância }\end{array}$ \\
\hline Tecnologia & $\begin{array}{l}\text { Processo de } \\
\text { produção } \\
\text { Processo de } \\
\text { serviço }\end{array}$ & $\begin{array}{l}\text { Intermitente } \\
\text { Contínuo } \\
\text { Tarefas. }\end{array}$ & $\begin{array}{l}\text { - Grau de automa- } \\
\text { - gão } \\
\text { Grau de rotina }\end{array}$ \\
\hline Rentabilidade & $\begin{array}{l}\text { Performance } \\
\text { económica }\end{array}$ & $\begin{array}{l}\text { Política de } \\
\text { financiamento }\end{array}$ & $\begin{array}{l}\text { - Margem bruta } \\
\text { - Margem opera } \\
\text { cional } \\
\text { - Margem líquida } \\
\text { - Grau de endivi- } \\
\text { damento }\end{array}$ \\
\hline
\end{tabular}

\section{O MODELO RELACIONAL}

De acordo com o paradigma teórico que explicitamos, as relaços esperadas esțo esquematizadas na figura 1.

A direção das setas indica a pressuposição de relação causal entre as variáveis.

Segundo o modelo, a estrutura organizacional é funçăo da tecnologia e da política intra-organizacional. Contudo, entre rede de influência política e estrutura organizacional, o pressuposto é de um tipo de relação em que a estrutura funciona também como meio de controle das forças de influência política dentro da organizaçăo.

No que diz respeito à performance econômica e financeira, o modelo pressupóe que a tecnologia e a política podem ser determinantes do desempenho da empresa, através, ou independentemente, da estrutura organizacional. Para investigar essas relaçoes, planejamos três etapas de pesquisa. A primeira etapa é de cunho descritivo e compreende a identificação:

a) de mudanças estruturais e tecnológicas;

b) de atores nas decisøes sobre formato estrutural, investimento e financiamento;
Figura 1

Modelo de análise relacional



c) das especializaçoes e da configuraçáo da atual estrutura das organizaçoes.

A segunda etapa analisa as relaçoes causais, isto é:

a) os efeitos das mudanças tecnológicas e da açăo política sobre a estrutura;

b) a relaçáo entre estrutura e performance econômica e financeira da empresa;

c) as relaçoes entre influência política e tecnologia e entre estas e a performance econômica da empresa.

$\mathrm{Na}$ terceira etapa, o trabalho é de caráter comparativo entre os grupos de empresas. A seleção da amostra foi feita para atender o objetivo desta análise comparativa, no caso, entre empresas estatais e privadas e entre empresas grandes e pequenas. A análise compreendé a comparação dos resultados encontrados na segunda etapa, no sentido de levantar se as diferenças observadas podem ser atriburdas à forma de propriedade (exercício do controle acionário) e/ou ao tamanho das empresas.

Não podemos deixar de observar que o conceito da empresa pequena, para fins de estudo, é pouco ortodoxo. Não se trata aqui de empresas realmente pequenas, com menos de 500 empregados, por exemplo. As empresas pequenas da nossa amostra, provavelmente, seriam classificadas na categoria de médias, dentro dos conceitos normalmente usados para classificação de empresas (Rattner et alii, 1979). No entanto, o que nos interessa e o tamanho relativo e, se a diferença de tamnho for muito grande, a análise comparativa pode ser inviável, pela falta de elementos comuns comparáveis.

1 Normas e regulamentos e especialistas em staff. (Perrow, 1972, p. 76). 


\section{REFERENCIAS BIBLIOGRĀFICAS}

Bacharach, Samuel B. \& Lawler, Edward J. Power and politics in organizations; the social psychology of conflict coalitions and bargaining. San Francisco, Jossey Bass, 1980.

Barbosa, A. L. Figueira. Propriedade e quase-propriedade no comércio de tecnologia. Brasılia, CNPq, 1981.

Bamard, Chester I. As funçōes do executivo. São Paulo, Atlas, 1971 .

Benakouche, Rabah. A tecnologia enquanto forma de acumulação. Economia e Desenvolvimento, Cortez, I(2), fev. 1982.

Blau, Peter M. \& Scott, W. Richard. Organizaçōes formais, uma abordagem comparativa. São Paulo, Atlas, 1977.

Braverman, Harry. Trabalho e capital monopolista; a degradação do trabalho no século XX. Rio de Janeiro, Zahar, 1977.

Coelho, Edmundo C. Tamanho. Tecnologia e intensidade administrativa. Revista de Administração de Empresas, Rio de Janeiro, 18(1): 31-9, jan./mar. 1978.

Dahrendorf, R. Class and class conflict in industrial society. Stanford, Calif., Stanford University Press, 1959. Apud: Bacharach, Samuel B. \& Lawler, Edward J. Power and politics in organizations; the social psychology of conflict, coalitions and bargaining. San Francisco, Jossey Bass, 1980.

Drucker, Peter F. Management. London, Pan, 1979.

Hall, Richard H., Organizations: structure and process. New Jersey, Prentice Hall, 1972.

Lawrence, Paul R. \& Lorsch, Jay W. As empresas e o ambiente; diferenciação e integraçฐ̃o administrativa. Petrópolis, Vozes, 1973.

Newbould, Gerald D. \& Lufftman, Georg A. Sucessful business policies. Westmead, Famborough, Hants, England, Gower Press Teakfield Reimited, 1978.
Perrow, Charles. Análise organizacional; um enfoque sociológico. Sð̃o Paulo, Atlas, 1972.

Pfeffer, Jeffrey. Power in organizations. Boston, Pitman, 1981.

Pugh, D. S.; Hickson, D. J. et alii. Dimensions of organization structure. Administrative Science Quartely, 13(1): 65-105, june 1968.

Rattner, Henrique; Durand, José Carlos G.; Rodrigues, Leôncio M. \& Micele, Sérgio. Pequena e média empresa no Brasil. São Paulo, Símbolo, 1979.

Rodrigues, Suzana B. \& Sá; Raquel R. Some aspects of organization structure in Brazil; the role of context and culture. Belo Horizonte, Curso de Mestrado em Administração da Universidade Federal de Minas Gerais, 1982.

Sabato, Jorge A. El comercio de tecnologia. Washington, Departamento de Assuntos Cientificos, Secretaria Geral da OEA, mar. 1972.

Simon, Herbert A. Comportamento administrativo; estudo dos processos decisórios nas organizaçбes administrativas. Rio de Janeiro, Fundação Getulio Vargas, 1979.

Solomon, Ezra. Teoria da administração financeira. Rio de Janeiro, Zahar, 1969.

Steer, Richard M. Problems in the measurement of organizational effectiveness. Administrative Science Quarterly, 20(4): 546-58, Dec. 1975.

Taylor, Frederick W. Princtipios de administração cientifica. São Paulo, 1963.

Thompson, James D. Organizations in action; social science bases of administrative theory. New York, McGraw-Hill, 1967.

Wood, Adrian. Uma teoria de lucros. Rio de Janeiro, Paz e Terra, 1980.

Woodward, Joan. Organização industrial: teoria e prática. São Paulo, Atlas, 1977.

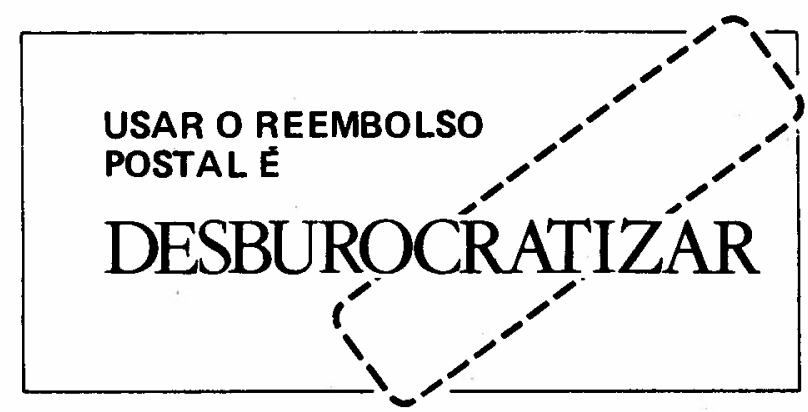

